\title{
Ethics of primate use
}

\author{
M. J. Prescott \\ National Centre for the Replacement, Refinement and Reduction of Animals in Research (NC3Rs), \\ 20 Park Crescent, London, W1B 1AL, UK
}

Received: 11 March 2010 - Revised: 21 September 2010 - Accepted: 19 October 2010 - Published: 12 November 2010

\begin{abstract}
This article provides an overview of the ethical issues raised by the use of non-human primates (NHPs) in research involving scientific procedures which may cause pain, suffering, distress or lasting harm. It is not an exhaustive review of the literature and views on this subject, and it does not present any conclusions about the moral acceptability or otherwise of NHP research. Rather the aim has been to identify the ethical issues involved and to provide guidance on how these might be addressed, in particular by carefully examining the scientific rationale for NHP use, implementing fully the 3Rs principle of Russell and Burch (1959) and applying a robust "harm-benefit assessment" to research proposals involving NHPs.
\end{abstract}

\section{Introduction}

\subsection{NHP use in scientific procedures}

NHPs are among the most extensively studied of all animals in the fields of behaviour, psychology, ecology, conservation and anthropology (see the PrimateLit bibliographic database: http://primatelit.library.wisc.edu/). They are also used in biomedical and biological research involving regulated scientific procedures, mainly in the fields of microbiology, immunology, neuroscience, biochemistry, pharmacology and toxicology, because their physiological and psychological similarities to humans make them high fidelity models $^{1}$ (Carlsson et al., 2004; Hau et al., 2000; Weatherall et al., 2006). The majority are Old World monkeys (macaques, vervet monkeys and baboons), both purpose-bred and wildcaught; New World monkeys, Prosimians and Great Apes (chimpanzees, Pan troglodytes) are also used ${ }^{2}$ (Carlsson et al., 2004; Conlee et al., 2004; European Commission, 2007; Hagelin, 2004; Rennie and Buchanan-Smith, 2005). An estimated 100 000-200 000 NHPs are used annually world-wide, mostly in the United States of America (USA), the European Union (EU) and Japan (Carlsson et al., 2004). Currently

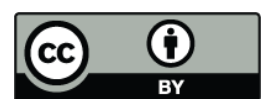

Correspondence to: M. J. Prescott (mark.prescott@nc3rs.org.uk)

${ }^{1}$ That is not to say that NHP models do not have limitations (e.g. Lewis and Johnson, 1995).

${ }^{2}$ The last recorded Great Ape use in the EU was in 1999 (6 chimpanzees). their use within the pharmaceutical industry is rising in line with the increasing number of biopharmaceuticals entering the drugs pipeline (Chapman et al., 2010; Hobson, 2000).

\subsection{Views on NHP use}

The use of NHPs in scientific procedures is one of the most contentious issues in science. At the time of writing, this issue is high on the political agenda in the EU, following a proposal from the European Commission (2008) to revise "Directive 86/609/EEC on the Protection of Animals Used for Experimental and Other Scientific Purposes" (European Community, 1986) and an opinion from its Scientific Committee on Health and Environmental Risks (2009) on "The need for non-human primates in biomedical research, production and testing of products and devices". The revision provides the opportunity for the EU Parliament and Council of Ministers to introduce new restrictions on NHP use. Although NHPs account for a very small proportion of the total number of vertebrate animals used in scientific procedures (0.09\% of those used in the EU in 2005: European Commission, 2007), opinion polls repeatedly show a high level of concern about their use amongst the general public (European Commission, 2006; New Scientist/MORI, 1999; Pifer et al., 1994). For example, more than $80 \%$ of respondents to the Commission's 2006 public consultation on animal experiments considered the use of NHPs to be not acceptable. 


\section{Glossary}

Deontological ethics: An approach to ethics that judges the morality of an action based on the action's adherence to a rule or rules. Deontologists look at rules and duties.

Transgenesis: The process of introducing foreign DNA into a genome.

Pharmacokinetics: A branch of pharmacology dedicated to the determination of the fate of substances administered externally to a living organism.

Phylogenetic: Relating to or based on evolutionary development or history.

Neurophysiological: Relating to the function of the nervous system.

Neurovirulence: The tendency or capacity of a microorganism to cause disease of the nervous system.

Theory of mind: The ability to attribute mental states (e.g. beliefs, desires and intentions) to oneself and others and to understand that others have beliefs, desires and intentions that are different from one's own.

Utilitarianism: The idea that the moral worth of an action is determined solely by its utility in providing happiness or pleasure as summed among all sentient beings. It is thus a form of consequentialism meaning that the moral worth of an action is determined by its outcome.

\section{Ethical frameworks and legal controls applied to NHP use}

The fundamental ethical dilemma raised by the use of NHP in experiments is the same as for the use of other animals: are we, human beings, morally justified in causing animals pain, suffering, distress and/or lasting harm in research aimed at alleviating or preventing human suffering, or furthering scientific knowledge. There is a wide spectrum of views on this issue in society, from those who consider all animal experiments to be immoral to those who believe few animal experiments to be unjustified if they benefit humans in some way (Nuffield Council on Bioethics, 2005). Moreover, many people hold varying opinions depending on the precise circumstances in question (e.g. the purpose of the research and the anticipated benefit, the species to be used, the level of harm caused to the animals involved). Therefore, most committees responsible for scrutinising the ethics of animal research proposals, whether at a institutional, local, regional or national level, aim to reach a collective decision, involving a diversity of perspectives and expertise (e.g. in the scientific area in question, animal welfare and ethics) (Animal Procedures Committee, 2009; de Greeve and de Leeuw, 1999; Home Office, 1998; Kolar, 2004).

\subsection{Utilitarianism and the harm-benefit assessment}

The approach to the ethical dilemma most often adopted is a pragmatic, utilitarian one. Utilitarianism requires us to strike the most favourable balance of benefits and costs for all the sentient individuals affected by what is proposed to be done. The underlying notion is that we can work out what is the ethical course of action by trading off one against the other (although this precept has been attacked by some moral philosophers). In the case of NHP research, the human interest in obtaining some benefit for mankind must be balanced against the interests of the NHPs in avoiding harm (Quigley, 2007).

This approach, referred to as a "cost-benefit assessment" or "harm-benefit assessment", forms the cornerstone of the United Kingdom (UK) Animals (Scientific Procedures) Act 1986 (ASPA) (UK Government, 1986). The Act is unique in explicitly requiring a harm-benefit assessment of every application to the Home Office for a project licence to conduct animal research. The European Commission (2008) intends that a harm-benefit assessment be part of the ethical evaluation of research projects by national regulatory authorities under the revised Directive 86/609/EEC, and there have been calls for such an assessment to be applied to NHP use in the USA (Conlee et al., 2004) .

\footnotetext{
${ }^{3}$ The Institutional Animal Care and Use Committees required in the USA under the amended 1966 Animal Welfare Act and 1985 Health Research Extension Act are concerned with animal care and use; not ethics.
} 


\subsection{The 3Rs}

The moral acceptability of animal research is less questionable where animal use and suffering are minimised, in line with the 3Rs principle of Russell and Burch (1959):

- Replacement of animals with non-animal methods;

- Reduction of the number of animals used to obtain information of a given amount and precision;

- Refinement of scientific procedures and husbandry to minimise suffering and improve animal welfare.

In addition to its value as an ethical framework for humane experiments, the 3Rs principle has considerable scientific merit and receives tacit support from the general public in opinion polls on animal experimentation (Ipsos MORI, 2009). Hence, it features in most codes of conduct on animal research and, in developed countries at least, scientists are required by law to apply something like it (European Community, 1986; Shoji, 2008; UK Government, 1986; United States Department of Agriculture, 1990). For example, Article 7 of Directive 86/609/EEC states "an experiment shall not be performed if another scientifically satisfactory method of obtaining the result sought, not entailing the use of an animal, is reasonably and practicably available" and "When an experiment has to be performed, the choice of species shall be carefully considered and, where necessary, explained to the authority. In a choice between experiments, those which use the minimum number of animals, involve animals with the lowest degree of neurophysiological sensitivity, cause the least pain, suffering, distress or lasting harm and which are most likely to provide satisfactory results shall be selected".

\subsection{Responsibilities}

There is broad support within the scientific and animal welfare communities for application of the 3Rs and a harmbenefit assessment to NHP research such that NHPs are only used in experiments where absolutely necessary (i.e. where no alternative methods are available), where morally justified, and where the numbers used and animal suffering are kept to the minimum (Boyd Group, 2002; Joint Working Group on Refinement, 2009; Scientific Committee on Health and Environmental Risks, 2009; Weatherall et al., 2006). Such judgements can only be made case-by-case for individual scientific objectives and projects (see Sect. 4) and usually involve the researcher, relevant ethics committee and/or national regulatory authority. Increasingly, public bodies funding NHP research, such as the European Commission, Medical Research Council, Biotechnology and Biological Sciences Research Council and Wellcome Trust, are also taking an active role in examining the necessity, justification and standards for such research (e.g. during the peer review of research grant applications) (Kolar, 2004; National Centre for the Replacement, Refinement and Reduction of Animals in Research, 2006a).

\subsection{Special legal provisions on NHPs}

In recognition of the high levels of public concern about NHP research, regulatory authorities in some countries have adopted strict measures on NHP use, effectively establishing ethical limits, giving rise to regulation which is a hybrid of deontological and utilitarian ethics. For example, under the UK ASPA, NHPs, together with cats, dogs and equines, can only be used where animals of no other species are suitable for achieving the scientific objective. Since 1995, there has also been an administrative ban on the use of Great Apes in scientific procedures (the UK Government will not issue licenses for their use), a ban on the use of wild-caught NHPs except where exceptionally and specifically justified, and further controls on the acquisition and use of NHPs (Home Office, 2000). Directive 86/609/EEC (European Community 1986) does not afford such special protection to NHPs (although "degree of neurophysiological sensitivity" is a consideration) but similar prohibitions are proposed for the revised Directive (see European Commission, 2008). There are special provisions under the USA Animal Welfare Act (United States Department of Agriculture, 1990) regarding environmental enhancement to promote the psychological well-being of captive NHPs, and governments in many nations have established accommodation and care requirements for these animals (Council of Europe, 2006; Home Office, 1989; National Research Council, 1996) (see Sect. 3.3).

\section{Are NHPs worthy of special concern?}

\subsection{What are the ethical issues?}

Many of the ethical issues associated with NHP use in scientific procedures are the same as those raised by the use of other vertebrate animals (Olsson et al., 2003):

- Exposure to painful or distressing scientific procedures and their effects, such as surgical interventions, infectious disease, or restraint - however, the suffering of NHPs may be different in kind from that of other animals (see Sect. 3.2);

- Housing in captive environments which limit freedom and may not meet species-typical needs, giving rise to physical or mental suffering (see Sect. 3.3) - these issues apply to breeding animals also;

- Death - very often this is required as an integral part of the experiment, because of the need to analyse tissues post mortem (see Sect. 3.4).

The purpose for which the animals are used can also raise ethical concerns (see Sect. 4.3), as can the application of new technologies (e.g. transgenesis: Olsson and Sandøe, 2009; 
Schatten and Mitalipov, 2009; Coors et al., 2010; engraftment of human neural stem cells: Greene et al., 2005).

In addition, practical issues related to the maintenance and use of NHPs raise ethical concerns that do not apply to most other animals used in research, for example:

- NHPs typically have long life spans and can spend years in captivity undergoing lengthy experiments (e.g. in behavioural neuroscience), continued use (e.g. in pharmacokinetics) or re-use in several independent studies during the course of their lives (see Sect. 4.2.2) (Carlsson et al., 2004; Rennie and Buchanan-Smith, 2005; Scientific Committee on Animal Health and Welfare, 2002).

- The inability of captive breeding colonies in the EU and USA to satisfy the research demand for macaques and other NHP species necessitates their importation from source countries in Asia, Africa and South America (Cohen, 2000; Hau and Schapiro, 2006; National Research Council, 2003; Prescott, 2001). The long, multi-staged journeys involved and the housing conditions, weaning and quarantine practices prior to importation can have ethical and animal welfare implications (Animal Procedures Committee, 2006; Fernstrom et al., 2008; Honess et al., 2004; Prescott and Jennings, 2004).

- Practically all of the NHPs used in research in the EU are purpose-bred, but most of the Old World monkeys used are the offspring of wild-caught parents (F1 generation) (Scientific Committee on Health and Environmental Risks, 2009). The capture and use of wildcaught NHPs for breeding for research has been criticised (Scientific Committee on Animal Health and Welfare, 2002), because of the stress, morbidity and mortality involved (International Primatological Society, 2007; Suleman et al., 1999, 2000). However, it has been argued that establishing and replenishing breeding colonies with wild-caught NHPs can be ethically justified where the animals are agricultural pests and would otherwise be killed (Stanley, 2003). To decrease reliance on wild-caught NHPs for breeding, the European Commission (2008) has proposed that after specific timelines only second generation (F2) animals born in captivity should be used in research.

\subsection{Suffering and the moral status of NHPs}

Many people, including from within the scientific community, consider that the use of NHPs in research is a matter of particular ethical concern because certain features NHPs share with humans, such as their highly developed nervous systems, cognitive complexity and intense sociality, have implications for the level or nature of suffering they might experience during experiments and are therefore morally relevant (Boyd Group, 2002; Nuffield Council on Bioethics, 2005;
Weatherall et al., 2006). It is extremely difficult to determine exactly the subjective experiences of non-human animals in relation to pain and suffering. However, the evolutionary continuum that is obvious from physiological, neurological and behavioural similarities between humans, NHPs and other animals allows us to make meaningful approximations.

A great deal is known about the nervous systems of NHP species (particularly macaques) from their use in invasive neuroscience research as a model of the human brain (Peretta, 2009). It seems plausible that NHPs have the potential to experience pain in a similar way to humans, given their neurophysiological complexity. However, the issue is not just response to pain, but the ability to anticipate and reflect upon pain, as well as for painful memories to endure after a painful episode, which could enhance any suffering (Bateson, 1991; Bermond, 2001; Lea, 2001). The evidence for reflective self-awareness of this kind is strongest for the Great Apes (Call and Tomasello, 2008; Parker et al., 1994), which raises serious questions about the morality of using them in harmful scientific procedures (Balls, 2007; Byrne, 1999; Knight, 2008). Such considerations have probably played an instrumental role in the decisions of some countries, including the UK, the Netherlands, Austria, Belgium, Sweden, New Zealand, Australia and Japan, to ban the use of Great Apes in biomedical research or place a strong moratorium on their use. To what extent biomedical researchers from these countries make use of Great Apes in countries where they still can be used, such as the USA, is not known.

Many characteristics of the Great Apes are considered indicators of "humanhood" or "personhood", such as their selfrecognition (and by implication self-awareness), rudimentary "theory of mind", linguistic abilities, distinct personalities, deep emotional attachments, and ability to pass on learned behaviours and customs through social mechanisms (Gómez, 1998; Scientific Committee on Animal Health and Welfare, 2002). This had led to calls to extend to Great Apes the same moral status afforded to humans and to confer on them the same legal rights as humans to life, individual liberty and freedom from torture (Anonymous, 2008; Bekoff, 1997; Cavalieri and Singer, 1993; Wise, 2000; The Great Ape Project: http://en.wikipedia.org/wiki/Great_Ape_Project).

The Old and New World monkeys more commonly used in research do not appear to share the most sophisticated mental abilities of Great Apes. Nonetheless, in the view of the Boyd Group, a forum for open exchange of views on issues of concern related to the use of animals in science "there is strong, though not incontestable, evidence that the general richness of monkeys' social lives and mental abilities means that compromising their way of life by using them in research and testing has the potential to cause them greater social and mental suffering than other laboratory species" (see Boyd Group, 2002 for a discussion of the evidence).

The intense sociality of NHPs is striking and suggests that they may suffer comparatively more than other 
commonly-used animals from confinement and relative social isolation. Certainly, the work of Harry Harlow and others (e.g. Harlow, 1958; Law, 2009; Rosenblum and Paully, 1987) on monkey cognition and social development has demonstrated that these animals have rich subjective lives filled with intention and emotion, and that disrupting their social bonds can cause depression-like states, with obvious ethical implications (Blum, 2002; Gluck, 1997; Novak and Suomi, 1991).

The relative moral status of monkeys compared with other laboratory animals, particularly social mammals such as cats, dogs, equines and pigs, is more contentious (e.g. Webster et al., 2010). As pointed out by the Boyd Group (2002), it is difficult generally to find ways of comparing the potential for suffering of any given species with another species. Moreover, it is difficult for us, as humans, to judge capacities for suffering in, or to empathise with, species which are evolutionarily more distant from us, and it might be argued that according any species of monkey special moral status reflects human prejudice in favour of species more like ourselves.

\subsection{Housing in captivity}

NHPs are essentially non-domesticated, wild animals mostly adapted to complex tropical habitats. Confining wild animals in captivity raises ethical concerns because it imposes upon them an environment vastly different from that in which they have evolved; if they are not able to adapt to the captive conditions, this can have a serious detrimental effect on their welfare (Carlstead, 1996). There is also a view that wild animals have a right to liberty (Rachels, 1976). Although functional simulations of many aspects of the natural environments of NHPs can be replicated in captivity (Hau and Schapiro, 2004) many scientists believe there are inherent difficulties in meeting the complex social, behavioural and psychological needs of NHPs in the laboratory environment and that the minimum standards of accommodation and care established by governments in many nations may not be sufficient to provide for their physical health and psychological well-being (Boyd Group, 2002; Buchanan-Smith et al., 2004; Faucheux et al., 1978; National Research Council, 1998; Novak and Suomi, 1988; Prescott and Buchanan-Smith, 2004; Reinhardt, 2004; Savage-Rumbaugh et al., 2007; Scientific Committee on Animal Health and Welfare, 2002; Wolfensohn and Honess, 2005). Accordingly, major investments to improve housing conditions for NHPs have been made in recent years, with increased attention given to environmental enrichment and social housing, which has undoubtedly improved animal welfare (e.g. Rudling, 2003; Kelly, 2008; Waitt et al., 2008; Wolfensohn, 2008). However, there remains considerable variation in standards between establishments which has led research funding bodies to develop their own higher standards for NHP research and to make adherence to them a condition of funding, wherever the research is conducted (Laboratory Animal Science Association/Medical
Research Council, 2004; National Centre for the Replacement, Refinement and Reduction of Animals in Research, 2006b).

\subsection{Fate of the animals}

The majority of NHPs used in experiments are euthanized, either because their tissues are required as part of the experiment or on compassionate grounds to alleviate unnecessary suffering. Whether it is morally wrong to prematurely end an animal's life is a subject of philosophical debate and beyond the scope of this chapter (see Regan, 1975). Apart from the philosophical question of whether an animal is harmed by being killed, in the case of highly sociable animals such as NHPs, the implications for other members of the social group of losing a group member also may raise ethical concerns.

In situations where death is not required, for example, in the case of surplus ex-research or ex-breeding NHPs, it is often possible to "retire" the animals and allow them to live out their natural life spans (Brent, 2004; Kerwin, 2006; Prescott, 2006; Seelig and Truitt, 1999). Some establishments choose this option on ethical grounds, where it is in the best interests of the animals concerned. NHPs are intelligent animals with which it is possible to develop strong emotional bonds (Bayne, 2002; Herzog, 2002); this can make euthanasia of NHPs difficult for staff to accept (Abbot, 2008).

In the case of chimpanzees no longer needed for biomedical research in the USA, retirement is a legal requirement under the 2000 Chimpanzee Health Improvement, Maintenance, and Protection Act. This Act established a system of sanctuaries to provide lifetime care for surplus chimpanzees, none of which may be subjected to euthanasia (except where it is in the best interests of the chimpanzee involved).

\section{Conducting ethical evaluations of NHP use}

Given the high level of concern about NHP use, it is important that ethical evaluations of primate experiments are robust and thorough. This requires case-by-case scrutiny of the necessity and justification for the use of NHPs, taking into account the importance of the science, the likelihood of success, the availability of alternatives, the real "added value" of NHPs over and above other species and methods, the number of animals to be used, and the total harms caused to the animals throughout their lifetimes. Only by considering these issues together can truly informed decisions be made about whether or not certain uses of NHPs are necessary, justified and ethical. Some considerations are given below, drawn from the author's experience. The focus is on NHP use in scientific procedures, but it is worth noting that even observational studies in the field can raise ethical issues, particularly if provisioning, capture or marking are involved (Fedigan, 2010; Gillespie et al., 2009; Jolly et al., 2003). 


\subsection{Is the NHP use scientifically necessary?}

In order to establish whether NHP use is scientifically necessary, the researcher should set out in detail the reasons why he/she believes that the particular scientific objective cannot be achieved by means other than the use of NHPs, or why NHPs offer very significant scientific advantages over all other possible alternative approaches (e.g. significantly improved predictive value). The importance of achieving the objective (e.g. in terms of the clinical need or commercial interests) is not relevant in this context. The rationale for NHP use should be critically examined by independent experts with a wide knowledge of the research field in question, including all available alternative approaches - not just those based on NHPs; this may require a wider than normal pool of scientific referees.

In most fields of research where NHPs are used, the scientific justification given for their use concerns their close similarity to humans, which it is argued makes them the best available model for defined scientific questions. However, generic appeals to this similarity should not be considered sufficient justification for NHP use. Instead, the rationale should be specific and founded on robust scientific considerations, such as the presence only in the NHP species of the anatomical structures, pathways, cognitive abilities or behaviours of interest. References and information should be provided which support the rationale and which demonstrate an active search for alternatives.

Various regulatory guidelines on toxicity and safety assessments of pharmaceuticals recommend that NHPs should only be used when it is scientifically demonstrated that none of the alternative rodent and/or non-rodent species commonly used in safety testing are appropriate for the purpose of the study (International Conference on Harmonisation, 2009; Smith and Trennery, 2002). Therefore, proposals to use NHPs for safety testing should receive as much scrutiny as those proposing their use in biomedical and biological research. NHPs should not be used as a default species, on the assumption that they will be the only species representative of humans (or the species most representative of humans) or because they have been used previously.

One of the main factors driving a rise in NHP use worldwide is the increasing development of monoclonal antibodies (mAbs) as therapies for diseases such as cancer and other immune-related conditions. mAbs are highly targetand species-specific, so NHPs, typically cynomolgus monkeys (Macaca fascicularis), are often the only relevant animal model for preclinical safety studies. However, there are safety-relevant differences between NHP and human immune systems, even between chimpanzees and humans, which means that NHPs are not always relevant for predicting human safety (Muller and Brennan, 2009); even where they posses the intended drug target, the pharmacological activity may not be the same as in man (Chapman et al., 2009, 2010). Where NHP use is necessary, careful thought should be given to species selection, taking into account scientific, animal welfare and practical considerations (Boyd Group, 2002; Smith et al., 2001).

\subsection{Have the $3 R$ s been applied fully?}

Widespread support for the 3Rs principle does not always translate into action on the ground, for a variety of reasons (e.g. Coulter et al., 2009; Lloyd et al., 2008; Prescott and Buchanan-Smith, 2007). Effective implementation of all three "R"s requires researchers, regulators and members of scientific and ethical review committees to be aware of existing 3Rs approaches and methods, to put the knowledge base into practice (not just around individual experiments, but also whole research programmes and strategies), and to keep abreast of developments in science and technology that can impact on the 3 Rs.

\subsubsection{Replacement}

Opportunities for replacing the use of NHPs in research and testing are currently limited, although in vitro methods, human volunteers, and genetically-altered rodents all have potential (Scientific Committee on Health and Environmental Risks, 2009). A more concerted and collaborative effort is needed to accelerate the development of replacement alternatives to NHP use, since this is the only way that the associated ethical issues can be addressed wholesale; this often gets overlooked in the rhetoric surrounding NHP use.

The use of rodents or other vertebrates in place of NHPs is not replacement as defined by Russell and Burch (1959) but may be ethically desirable if an assessment of the available evidence suggests that the non-primate species is likely to suffer less harm. The judgements in such cases can be complex: for example, the transgenic mouse model for neurovirluence and potency testing of poliomyelitis vaccines avoids NHPs but involves greater numbers of animals and more severe endpoints (Dragunsky et al., 2003).

\subsubsection{Reduction}

There is considerable scope for reduction where NHP use is currently unavoidable. Appropriate design of experiments is critical and greater consideration should be given to this during peer review of research proposals and scientific manuscripts (Kilkenny et al., 2009). The number of animals used in each experiment should be the minimum sufficient to answer the question posed, and researchers should justify the number of animals required, including sample size calculations where appropriate. Estimates of the number of animals needed should, where possible, take into account the required statistical significance and power level, the likely magnitude of the treatment effect (or other outcomes), the population variance and the factors that might affect this. Opportunities to further reduce the number of animals used, for example 
by careful planning and scheduling of breeding and experiments, should be exploited.

Sharing of study designs, data and experience, particularly in industry, can lead to significant reductions in NHP use (even without the need for regulatory change). For example, a data-sharing collaboration between the NC3Rs and pharmaceutical and biotechnology companies world-wide has identified opportunities to up to halve the number of NHPs used in the development of mAbs by decreasing the number of dose groups, recovery animals and chronic studies performed (Chapman et al., 2009). Hence, it is important to adopt a flexible, case-by-case approach to study design and drug development, based on strong scientific rationales.

Exploitation of modern technologies (e.g. in vivo imaging, telemetry systems, multi-unit electrophysiological recording techniques) can lead to reduction, for example, through increased data yield per animal and/or experiment (Baker et al., 1999; Kinter and Johnsen, 1999; t'Hart et al., 2006). Banking and sharing of tissues within and between establishments is another means of optimising and reducing NHP use.

The re-use of NHPs can decrease the number of animals used overall and may be driven by ethical, practical and economic considerations. However, there are ethical considerations against as well as in favour of re-use (van Vlissingen, 1999). The actual or potential harms to the animals concerned (e.g. from long-term housing and the cumulative effects of previous procedures) must be weighed against the welfare cost of obtaining and housing (and in some cases surgically-preparing) naïve animals. In the UK, re-use is subject to legal constraints (Home Office, 2000) and a reduction in the overall number of NHPs used is not considered to justify causing a significant increase in harms for individual animals. Similarly, the European Commission (2008) proposes to restrict the circumstances in which animals can be re-used in order to limit the harm caused to individual animals.

\subsubsection{Refinement}

Refinement is misunderstood by many researchers (National Centre for the Replacement, Refinement and Reduction of Animals in Research, 2008); it refers to any approach which avoids or minimises the actual or potential pain, distress and other adverse effects experienced at any time during the life of the animals involved, and which enhances their wellbeing (Buchanan-Smith et al., 2005). Refinement is important not just for ethical reasons, but also for scientific reasons because an animal's welfare state can affect its suitability as a research model. Developments in animal welfare science are providing increasingly more sophisticated and reliable measures of animal suffering and well-being (e.g. Mendl et al., 2009).

Many opportunities exist to refine the use and care of NHPs and much guidance is available in the scientific literature (see Rennie and Buchanan-Smith, 2006a, b, c and Joint Working Group on Refinement, 2009 for recent re- views). Researchers should ensure that every aspect of the lifetime experience of the animals is refined, including sourcing and transport; housing and husbandry; experimental design and techniques; handling; care of the animals before, during and after each procedure; end-points of the procedures; and method of killing (or other fate at the end of the experiments). The possibilities for further refinements should be continually reviewed throughout the research programme.

The high intelligence of NHPs permits behavioural management techniques to be used to reduce the amount of stress experienced during capture, transport, maintenance and research use; such techniques should be integrated into human-NHP interactions (Prescott and Buchanan-Smith, 2003; Prescott et al., 2005; Schapiro et al., 2005). Establishing appropriate relationships with NHPs is important for animal welfare generally and is of special relevance to many types of NHP research where the researchers depend on the co-operation of the animal to perform behavioural and cognitive tasks (Prescott et al., 2010)

\subsection{Is the NHP use morally justified?}

Even where it is necessary to use NHPs to achieve a particular scientific objective, and the 3Rs have been full applied, it does not mean that it is right to do so. What one person may consider a morally justified use of NHPs another may not (e.g. see the exchange of views on stroke research: Degeling and Johnson, 2009; Fox, 2009; Gerrek, 2009; Nobis, 2009; Sughrue et al., 2009a, b; and endotoxic shock: James, 2006; Wolfensohn et al., 2006; Yin et al., 2005, 2006). In practice, the test of the moral justifiability of NHP use in scientific procedures is whether or not the likely harms caused to the NHPs involved are outweighed by the anticipated benefit for humans (or other animals or the environment) A critical question is: what counts as a significantly important benefit?

A focus of the animal protection community has been the use of NHPs in fundamental research. Such research produces information that may come to be useful in understanding and treatment of disease, but is mainly pursued with the aim of advancing general knowledge in the biological sciences. For example, much neuroscience research using NHPs is conducted to understand how the structure and function of the brain contributes to perception, thinking, emotion and motor control (e.g. how brain circuits enable us to see, remember what we have seen, or to reach out and grasp an object). Some people deny that such experimentation plays a vital role in the delivery of substantial new human health benefits, or consider it to have less value than applied research (German, 2008; Martin, 2009; Sauer, 2004; Schiermeier, 2008). After lobbying on this issue by animal protection groups, the European Commission (2008) proposed to limit NHP use under the revised Directive 86/609/EEC to procedures "undertaken with a view to the avoidance, prevention, diagnosis or treatment of life-threatening or debilitating 
clinical conditions in human beings", but faced counterlobbying by the bioscience community (Olsson and Vitale, 2010). Whilst there have been serendipitous medical advances stemming from the unexpected outcomes of fundamental research, there has never been a robust and systematic retrospective review of the value and impact of such research and whether the scientific advances in the field have been solely dependent on the use of NHPs. This makes generic statements about NHP use being essential for improving human health difficult to substantiate.

In order for a robust harm-benefit assessment to be undertaken, the researcher should set out the anticipated benefits in precise and realistic terms, the likelihood of success, all of the harms caused to the animals (with an indication of the nature, frequency, duration and overall severity of animal suffering), any ethical issues arising from the proposed work, and why he/she personally considers that the potential benefits outweigh the harms. Members of the ethics committee must then make their own judgements about whether the likely human dividends are substantial enough to outweigh the animal suffering (for practical guidance on making such judgements, see Animal Procedures Committee, 2003; Smith and Boyd, 1991). Discussion and debate between committee members will help to clarify the issues and decide opinions. There may be disagreement about what is morally acceptable, in which case the consensus view is usually adopted. Whatever the ultimate decision, it should be defensible in the public arena.

Acknowledgements. Thanks to Vicky Robinson (NC3Rs) for helpful comments on the manuscript.

Edited and reviewed by: E. W. Heymann

\section{References}

Abbott A (2008) French university under fire for culling macaques. Nature 455:145

Animal Procedures Committee (2003) Review of cost-benefit assessment in the use of animals in research. London: Home Office

Animal Procedures Committee (2006) Acceptance of overseas centres supplying non-human primates to UK laboratories: a report by the Primates Sub-Committee of the Animal Procedures Committee. London: Animal Procedures Committee

Animal Procedures Committee (2009) Report of the Animal Procedures Committee for 2008. London: The Stationery Office.

Anonymous (2008a) Experimental use of nonhuman primates is not a simple problem. Nature Medicine 14:1011-1013

Anonymous (2008b) Apes get legal rights in Spain. Lab Prim News 47(4):11

Baker SN, Philbin N, Spinks R, Pinches EM, Wolpert DM, MacManus DG, Pauluis Q, Lemon RN (1999) Multiple single unit recording in the cortex of monkeys using independently moveable microelectrodes. J Neurosci Meth 94:5-17

Balls M (2000) Proponent's statement: Moving toward the zero option for the use of non-human primates as laboratory animals. In: Balls M, van Zeller AM, Halder M (eds) Progress in the re- duction, refinement and replacement of animal experimentation: developments in animal and veterinary sciences 31B. Oxford: Elsevier. $1587-1591$

Balls M (2007) Time for real action on chimpanzees and other hominids. ATLA - Altern Lab Anim 35:191-195

Bateson P (1991) Assessment of pain in animals. Anim Behav 42:827-839

Bayne K (2002) Development of the human-research animal bond and its impact on animal well-being. ILAR Journal 43(1):4-9

Bekoff M (1997) Deep ethology, animal rights, and the great ape/animal project: resisting speciesism and expanding the community of equals. J Agric Environ Ethics 10:269-296

Bermond B (2001) A neurophysiological and evolutionary approach to animal consciousness and animal suffering. Anim Welfare 10:S47-S62

Blum D (2002) Love at Goon Park: Harry Harlow and the science of affection. Cambridge, Massachusetts: Perseus Publishing

Boyd Group (2002) The Boyd Group papers on the use of nonhuman primates in research and testing. Leicester: The British Psychological Society

Brent L (2004) Solutions for research chimpanzees. Lab Anim 33:37-43

Buchanan-Smith HM, Prescott MJ, Cross NJ (2004) What factors should determine cage sizes for primates in the laboratory? Anim Welfare 13(S1):197-201

Buchanan-Smith HM, Rennie AE, Vitale A, Pollo S, Prescott MJ, Morton DB (2005) Harmonising the definition of refinement. Anim Welfare 14:379-384

Byrne RW (1999) Primate cognition: evidence for the ethical treatment of primates. In: Dolins FL (ed) Attitudes to animals. Cambridge, UK: Cambridge University Press. 114-125

Call J, Tomasello M (2008) Does the chimpanzee have a theory of mind?: 30 years later. Trends Cog Sci 12:187-192

Carlsson HE, Schapiro SJ, Farah I, Hau J (2004) Use of primates in research: a global overview. Am J Primatol 63:225-237

Carlstead K (1996) Effects of captivity on the behaviour of wild mammals. In: Kleiman DG, Allen MR, Thompson KV, Lumpkin $\mathrm{S}$, Harris H (eds) Wild mammals in captivity. Chicago: University of Chicago Press. 317-333

Cavalieri P, Singer P (eds.) (1993) The great ape project: equality beyond humanity. London: Fourth Estate

Chapman K, Pullen N, Coney L, Dempster M, Andrews L, Bajramovic J, Baldrick P, Buckley L, Jacobs A, Hale G, Green C, Ragan I, Robinson V (2009) Preclinical development of monoclonal antibodies: considerations for the use of non-human primates. mAbs 1:500-511

Chapman K, Pullen N, Andrews L, Ragan N (2010) The future of non-human primate use in mAb development. Drug Discov Today, Jan 19 (Epub. ahead of print)

Cohen J (2000) Vaccine studies stymied by shortage of animals. Science 287:959-960

Conlee KM, Hoffeld EH, Stephens ML (2004) Demographic analysis of primate research in the United States. ATLA - Altern Lab Anim 32(S1):315-322

Coors ME, Glover JJ, Juengst ET, Sikela JM (2010) The ethics of using transgenic non-human primates to study what makes us human. Nature Reviews Genetics 11:658-662

Coulter CA, Flecknell PA, Richardson CA (2009) Reported analgesic administration to rabbits, pigs, sheep, dogs and non- 
human primates undergoing experimental surgical procedures. Lab Anim 43:232-238

Council of Europe (2006) Appendix A of the European Convention for the Protection of Vertebrate Animals Used for Experimental and Other Scientific Purposes (ETS 123). Guidelines for Accommodation and Care of Animals (Article 5 of the Convention). Approved by the Multilateral Consultation. Cons 123 (2006) 3. Strasbourg: Council of Europe

Degeling C, Johnson J (2009) Lost in translation: gaps in reasoning for primate stroke. Am J Bioethics 9(5):23-25

de Greeve P, de Leeuw W (1999) Ethics committees in Europe an overview. In Zak O, Sande MA (eds) Handbook of animal models of infection. San Diego: Academic Press. 13-18

Dragunsky E, Nomura T, Karpinski K, Furesz J, Wood DJ, Pervikov Y, Abe S, Kurata T, Vanloocke O, Karganova G, Taffs R, Heath A, Ivshina A, Levenbook I (2003) Transgenic mice as an alternative to monkeys for neurovirulence testing of live oral poliovirus vaccine: a validation by a WHO collaborative study. Bull World Health Organ 81:251-260

Eurogroup for Animal Welfare (2005) Call to end the use of non-human primates in biomedical research and testing from animal protection organisations worldwide. Berlin, August 2005. (online) http://www.eurogroupforanimals.org/policy/pdf/ ngosprimateresolutionaug05.pdf

European Commission (2006) Results of questionnaire for the general public on the revision of Directive 86/609/EEC on the protection of animals used for experimental and other scientific purposes. (online) http://ec.europa.eu/environment/chemicals/lab_ animals/pdf/results_citizens.pdf

European Commission (2007) Fifth report from the Commission to the Council and the European Parliament on the statistics on the number of animals used for experimental and other scientific purposes in the member states of the European Union. (online) http://ec.europa.eu/environment/chemicals/lab_animals/ reports_en.htm

European Commission (2008) Proposal for a directive of the European Parliament and of the Council on the protection of animals used for scientific purposes (presented by the Commission) \{SEC(2008) 2410\}\{SEC(2008) 2411\}. Brussels: European Commission. http://ec.europa.eu/environment/chemicals/ lab_animals/proposal_en.htm

European Community (1986). Council Directive 86/609/EEC on the approximation of laws, regulations and administrative provisions of the member states regarding the protection of animals used for experimental and other scientific purposes, OJ L358. Luxembourg: Official Journal of the European Communities

Faucheux B, Bertrand M, Bouliere F (1978) Some effects of living conditions upon the pattern of growth in the stumptailed macaque (Macaca arctoides). Folia Primatol 30:220-236

Fedigan LM (2010) Ethical issues faced by field primatologists: asking the relevant questions. Am J Primatol 72:754-771

Fernstrom AL, Sutian W, Royo F, Westlund K, Nilsson T, Carlsson HE, Paramastri Y, Pamungkas J, Sjuthi D, Schapiro SJ, Hau J (2008) Stress in cynomolgus monkeys (Macaca fascicularis) subjected to long-distance transport and simulated transport housing conditions. Stress 11:467-476

Fox M (2009) The legal regulation of primate research. Am J Bioethics 9(5):13-15

German UG (2008) Public opinion and the ethics of brain research.
Nature 456:443

Gerrek ML (2009) Primate stroke research: still not interested. Am J Bioethics 9(5):29-30

Gillespie TR, Rwego IB, Leendertz FH, Travis D (2009) Ethical considerations for field-based investigations of primate disease. Am J Primatol 71(S1):31

Gluck JP (1997) Harlow and animal research: reflection on the ethical process. Ethics Behav 7:149-161

Gómez JC (1998) Are apes persons? The case for primate intersubjectivity. Etica e Animali 9:51-63

Greene M, Schill M, Takahashi S, Bateman-House A, Beauchamp T, Bok H, Cheney D, Coyle J, Deacon T, Dennett D, Donovan P, Flanagan O, Goldman S, Greely H, Martin L, Miller E, Mueller D, Siegel A, Solter D, Gearhart J, McKhann G, Faden R (2005) Moral issues of human-non-human primate neural grafting. Science 309:385-386.

Hagelin J (2004) Survey on the use of nonhuman primates in $\mathrm{Eu}-$ rope. Primate Rep 69:3-13

Harlow HF (1958) The nature of love. Am Psychol 13:673-685

Hau J, Farah IO, Carlsson HE, Hagelin J (2000) Opponents' statement: non-human primates must remain accessible for vital biomedical research. In: Balls M, van Zeller AM, Halder M (eds) Progress in the reduction, refinement and replacement of animal experimentation: developments in animal and veterinary sciences 31B. Oxford: Elsevier. 1593-1601

Hau J, Schapiro SJ (2004) The welfare of non-human primates. In: Kaliste E (ed) The welfare of laboratory animals. The Netherlands: Kluwer Academic Publishers. 291-314

Hau J, Schapiro SJ (2006) Non-human primates in biomedical research. Scand J Lab Anim Sci 33:9-12

Herzog H (2002) Ethical aspects of relationships between humans and research animals. ILAR J 43:27-32

Hobson W (2000) Safety assessment studies in nonhuman primates. Int J Toxicol 19:141-147

Home Office (1998) Statement: the ethical review process, 1 April 1998. (online) http://scienceandresearch.homeoffice.gov. uk/animal-research/publications-and-reference/publications/ guidance/ethical-review-process/ethicalprocess.pdf

Home Office (1989) Code of practice for the housing and care of animals used in scientific procedures. London: HMSO

Home Office (2000) Guidance on the Operation of the Animals (Scientific Procedures) Act 1986. London: HMSO

Honess PE, Johnson PJ, Wolfensohn SE (2004) A study of the behavioural responses of non-human primates to air transport and re-housing. Lab Anim 38:119-132

Humane Society of the United States (2009) Using primates in medical experimentation is unjustifiable. In: Lankford RD (ed) Animal experimentation. Farmington Hill, MI: Greenhaven Press. 74-78

International Conference on Harmonisation (2009) ICH Topic M3 (R2) Non-clinical safety studies for the conduct of human clinical trials and marketing authorization for pharmaceuticals. Step 4. Note for guidance on non-clinical safety studies for the conduct of human clinical trials and marketing authorization for pharmaceuticals (CPMP/ICH/286/95). (online) http://www.ema. europa.eu/pdfs/human/ich/028695en.pdf

International Primatological Society (2007) IPS international guidelines for the acquisition, care and breeding of nonhuman primates, 2nd edition. (online) 
http://www.internationalprimatologicalsociety.org/docs/

IPS_International_Guidelines_for_the_Acquisition_Care_and_

Breeding_of_Nonhuman_Primates_Second_Edition_2007.pdf

Ipsos MORI (2009) Views on animal experimentation. (online) http://www.ipsos-mori.com/Assets/Docs/Polls/ views-on-animal-experimentation-2009.pdf

James A (2006) Endotoxic shock model with fluid resuscitation in Macaca mulatta. Lab Anim 40:103

Joint Working Group on Refinement (2009) Refinements in husbandry, care and common procedures for non-human primates: Ninth report of the BVAAWF/FRAME/RSPCA/UFAW Joint Working Group on Refinement (Jennings M, Prescott MJ, eds). Lab Anim 43(S1):1-47

Jolly CJ, Phillips-Conroy JE, Mueller AE (2003) Trapping primates. In: Setchell JM, Curtis DJ (eds) Field and laboratory methods in primatology: a practical guide. Cambridge: Cambridge University Press. 110-121

Kelly J (2008) Implementation of permanent group housing for cynomolgus macaques on a large scale for regulatory toxicology studies. AATEX 14: S107-S110

Kerwin AM (2006) Overcoming the barriers to retirement of Old and New World monkeys from research facilities. J Appl Anim Welf Sci 9:337-347

Kilkenny C, Parsons N, Kadyszewski E, Festing MFW, Cuthill IC, Fry D, Hutton J, Altman DG (2009) Survey of the quality of experimental design, statistical analysis and reporting of research using animals. PLoS ONE 4(11) e7824 (online)

Kinter LB, Johnsen DK (1999) Remote monitoring of experimental endpoints in animals using radiotelemetry and bioimpedance technologies. In: Hendriksen CFM, Morton DB (eds) Humane endpoints in animal experiments in biomedical research. London: Royal Society of Medicine Press. 58-65

Kolar R (2004) Ethical evaluation of research proposals by ethics panels advising the European Commission. ATLA - Altern Lab Anim 32:429-439

Knight A (2008) The beginning of the end for chimpanzee experiments? Philos Ethics Humanit Med 3. p. 16 (online) http: //www.peh-med.com/content/3/1/16

Laboratory Animal Science Association / Medical Research Council (2004) Key considerations in the breeding of macaques and marmosets for research purposes. (online) www.mrc.ac.uk/ Utilities/Documentrecord/index.htm?d=MRC003342

Law AJ, Pei Q, Walker M, Gordon-Andrews H, Weickert CS, Feldon J, Pryce CR, Harrison PJ (2009) Early parental development in the marmoset monkey produces long-term changes in hippocampal expression of genes involved in synaptic plasticity and implicated in mood disorder. Neuropsychopharmacology 34:1381-1394

Lea SEG (2001) Anticipation and memory as criteria for special welfare consideration. Anim Welfare 10:S195-S208

Lewis AD, Johnson PR (1995) Developing animal models for AIDS research: progress and problems. Trends Biotechnol 13:142-150

Lloyd MH, Foden BW, Wolfensohn SE (2008) Refinement: promoting the 3Rs in practice. Lab Anim 42:284-293

Martin KAC (2009) Research on primate brains is scrutinized and must be justified. Nature 457:257

Mendl M, Burman O, Parker R, Paul E (2009) Cognitive bias as an indicator of animal emotion and welfare: emerging evidence and underlying mechanisms. App Anim Behav Sci 118:161-181
Muller PY, Brennan FR (2009) Safety assessment and dose selection for first-in-human clinical trials with immunomodulatory monoclonal antibodies. Clin Pharmacol Ther 85:247-58

National Centre for the Replacement, Refinement and Reduction of Animals in Research (2006a) Peer review. (online) www.nc3rs. org.uk/peerreview

National Centre for the Replacement, Refinement and Reduction of Animals in Research (2006b) NC3Rs guidelines: primate accommodation, care and use. London: NC3Rs

National Centre for the Replacement, Refinement and Reduction of Animals in Research (2008) Views on the 3Rs: survey report 2008. (online) www.nc3rs.org.uk/opinionsurvey

National Research Council (1996) Guide for the care and use of laboratory animals. Washington, D.C.: National Academy Press

National Research Council (1998) The psychological well-being of nonhuman primates. Washington, D.C.: National Academy Press

National Research Council (2003) International perspectives: the future of nonhuman primate resources: proceedings of the workshop held April 17-19, 2002. Washington, D.C.: National Academy Press

New Scientist/MORI (1999) Attitudes towards experimentation on live animals http://www.ipsos-mori.com/researchpublications/ researcharchive/poll.aspx?oItemId $=1882$

Nobis N (2009) Interests and harms in primate research. Am J Bioethics 9(5):27-29

Novak MA, Suomi SJ (1988) Psychological well-being of primates in captivity. Am Psychol 43:765-773

Novak MA, Suomi SJ (1991) Social interaction in nonhuman primates: an underlying theme for primate research. Lab Anim Sci 41:308-314

Nuffield Council on Bioethics (2005) The ethics of research involving animals. London: Nuffield Council on Bioethics

Olsson AS, Vitale A (2010) Legislation, social licence and primate research. EMBO Reports 11:9

Olsson AS, Sandøe P (2009) "What's wrong with my monkey?": ethical perspectives on germline transgenesis in marmosets. Transgenic Research, 19 Aug 192009 (Epub ahead of print) www.springerlink.com/content/34737hr1527k7762/

Olsson AS, Robinson P, Pritchett K, Sandøe P (2003) Animal research ethics. In: Hau J, Van Hoosier Jr, GL (eds) Handbook of laboratory animal science, 2nd edition: vol. 1, essential principles and practices. Boca Raton: CRC Press. 13-30

Parker ST, Mitchell RW, Boccia ML (eds) (1994) Self-awareness in animals and humans. New York: Cambridge University Press

Peretta G (2009) Non-human primate models in neuroscience research. Scand J Lab Anim Sci 36:77-85

Pifer L, Shimizu K, Pifer R (1994) Public attitudes toward animal research: some international comparisons. Soc Anim 2:95-113

Prescott MJ (2001) Counting the cost: welfare implications of the supply and transport of non-human primates for use in research and testing. Horsham, West Sussex: Royal Society for the Prevention of Cruelty to Animals

Prescott MJ (2006) Finding new homes for ex-laboratory and surplus zoo primates. Lab Prim Newsl 45(3):5-8

Prescott MJ, Buchanan-Smith HM (eds) (2003) Training nonhuman primates using positive reinforcement techniques. J AAWS 6(3):157-161

Prescott MJ, Buchanan-Smith HM (2004) Cage sizes for tamarins in the laboratory. Anim Welfare 13:151-158 
Prescott MJ, Buchanan-Smith HM (2007) Training laboratoryhoused non-human primates, part 1: a survey of current practice in the UK. Anim Welfare 16:21-36

Prescott MJ, Jennings M (2004) Ethical and welfare implications of the acquisition and transport of non-human primates for use in research and testing. ATLA - Altern Lab Anim 32(S1A):323327

Prescott MJ, Bowell VA, Buchanan-Smith HM (2005) Training laboratory-housed non-human primates, part 2: developing and implementing training programmes. Anim Technol Welfare 4:133-148

Prescott MJ, Brown VJ, Flecknell PA, Gaffan D, Garrod K, Lemon RN, Parker AJ, Ryder K, Schultz W, Scott L, Watson J, Whitfield L (2010) Refinement of the use of food and fluid control as motivational tools for macaques used in behavioural neuroscience research: Report of a working group of the NC3Rs. J Neurosci Methods 193:167-188 http://dx.doi.org/10.1016/j. jneumeth.2010.09.003

Quigley M (2007) Non-human primates: the appropriate subjects of biomedical research? J Med Ethics 33:655-658

Rachels J (1976) Do animals have a right to liberty? In: Regan T, Singer P (eds) Animal rights and human obligations. Englewood Cliffs: Prentice Hall. 205-223

Regan T (1975) The moral basis of vegetarianism. Can J Philosophy 5(2):181-214

Reinhardt V (2004) Flaws in federal regulations pertaining to the welfare of primates kept in research institutions. J Appl Anim Welf Sci 7:273-276

Rennie A, Buchanan-Smith HM (2005) Report on the extent and character of primate use in scientific procedures across Europe in 2001. Lab Prim Newsl 44(2):6-12

Rennie AE, Buchanan-Smith HM (2006a) Refinement of the use of non-human primates in scientific research, part I: the influence of humans. Anim Welfare 15:203-213

Rennie AE, Buchanan-Smith HM (2006b) Refinement of the use of non-human primates in scientific research, part II: housing, husbandry and acquisition. Anim Welfare 15:215-238

Rennie AE, Buchanan-Smith HM (2006c) Refinement of the use of non-human primates in scientific research, part III: refinement of procedures. Anim Welfare 15:239-261

Rosenblum LA, Paully GS (1987) Primate models of separationinduced depression. Psychiatr Clin North Am 10:437-447

Rudling W (2003) Primate housing - a new approach. Anim Technol Welfare 2:143-150

Russell WMS, Burch RL (1959) The principles of humane experimental technique. Wheathampstead: Universities Federation for Animal Welfare

Sauer UG (2004) The moral standing of non-human primates: why they merit special consideration. ATLA - Altern Lab Anim 32(S1):309-313

Savage-Rumbaugh S, Wamba K, Wamba P, Wamba N (2007) Welfare of apes in captive environments: comments on, and by, a specific group of apes. J Appl Anim Welf Sci 10:7-19

Schapiro SJ, Perlman JE, Thiele E, Lambeth S (2005) Training nonhuman primates to perform behaviors useful in biomedical research. Lab Animal 34:37-42

Schatten G, Mitalipov S (2009) Developmental biology: transgenic primate offspring. Nature 459:515-516

Schiermeier Q (2008) German authority halts primate work. Nature
455:1159

Scientific Committee on Animal Health and Welfare (2002) The welfare of non-human primates used in research. Brussels: Health and Consumer Protection Directorate-General, European Commission

Scientific Committee on Health and Environmental Risks (2009) The need for non-human primates in biomedical research, production and testing of products and devices. Brussels: European Commission http://ec.europa.eu/health/ph_risk/committees/04_ scher/docs/scher_o_110.pdf

Seelig D, Truitt A (1999) Post-research retirement of monkeys and other primates. Lab Prim Newsl 38(2):1-4

Shoji K (2008) Japanese concepts and government policy on animal welfare and animal experiments. AATEX 14:179-181

Smith D, Trennery P (2002) Non-rodent selection in pharmaceutical toxicology: a 'points to consider' document developed by the ABPI in conjunction with the UK Home Office. London: Association of the British Pharmaceutical Industry. 1-8 http://www. abpi.org.uk/publications/pdfs/final_pharma-toxicology.pdf

Smith D, Trennery P, Farningham D, Klapwijk J (2001) The selection of marmoset monkeys (Callithrix jacchus) in pharmaceutical toxicology. Lab Anim 35:117-130

Smith JA, Boyd KM (1991) Lives in the balance: the ethics of using animals in biomedical research. Oxford: Oxford University Press

Stanley MA (2003) The breeding of naturally occurring B virusfree cynomolgus monkeys (Macaca fascicularis) on the island of Mauritius. In: International perspectives: the future of nonhuman primate resources: proceedings of the workshop held April 1719, 2002. Washington, D.C.: National Research Council. 46-48

Sughrue ME, Mocco J, Mack WJ, Ducruet AF, Komotar RJ, Fischbach RL, Martin TE, Connolly ES Jr (2009a) Response to open peer commentaries on "bioethical considerations in translational research: primate stroke". Am J Bioethics 9(5):W1-W3

Sughrue ME, Mocco J, Mack WJ, Ducruet AF, Komotar RJ, Fischbach RL, Martin TE, Connolly ES Jr (2009b) Bioethical considerations in translational research: primate stroke. Am J Bioethics 9(5):3-12

Suleman MA, Yole D, Wango E, Sapolsky R, Kithome K, Carlsson HE, Jau J (1999) Peripheral blood lymphocyte immunocompetence in wild African green monkeys (Cercopithecus aethiops) and the effects of capture and confinement. In Vivo 13:25-27

Suleman MA, Wango E, Farah IO, Hau J (2000) Adrenal cortex and stomach lesions associated with stress in wild male African green monkeys (Cercopithecus aethiops) in the post-capture period. J Med Primatol 29:338-342

t'Hart BA, Smith P, Amor S, Strijkers GJ, Blezer ELA (2006) MRIguided immunotherapy development for multiple sclerosis in a primate. Drug Discov Today 11:58-66

Thew M, Seymour E (2009) The science and ethics of primate research. Lancet 374:607-608

UK Government (1986) Animals (Scientific Procedures) Act 1986. London: HMSO

United States Department of Agriculture (1990) Animal Welfare Act as Amended (7 USC, 2131-2156) http://www.nal.usda.gov/ awic/legislat/awa.htm

van Vlissingen JMF (1999) The re-use of animals for research: a humane endpoint. In Hendriksen CFM, Morton DB (eds) Humane endpoints in animal experiments for biomedical research: proceedings of the international conference, 22-25 November 1998 , 
Zeist, the Netherlands. London: Royal Society of Medicine Press. 145-147

Yin GW, Qiu HB, Du KH, Tang JQ, Liu CP, Fang ZX (2005) Endotoxic shock model with fluid resuscitation in Macaca mulatta. Lab Anim 39:269-279

Yin GW, Qiu HB, Du KH, Tang JQ, Liu CP, Fang ZX (2006) Endotoxic shock model with fluid resuscitation in Macaca mulatta: the authors' reply. Lab Anim 40:104-106

Waitt CD, Honess PE, Bushmitz M (2008) Creating housing to meet the behavioral needs of long-tailed macaques. Lab Prim Newsl 47(4): $1-5$

Weatherall D, Goodfellow P, Harris J, Hinde R, Johnson L, Morris R, Ross N, Skehel J, Tickell C (2006) The use of non-human primates in research. London: Academy of Medical Sciences
Webster J, Bollen P, Grimm H, Jennings M (2010) Ethical implications of using the minipig in regulatory toxicology studies. J Pharmacol Toxicol Methods, May 31 [Epub ahead of print] doi:10.1016/j.vasen.2010.05.002

Wise S (2000) Rattling the cage: toward legal rights for animals. Cambridge, MA: Perseus Publishing

Wolfensohn S (2008) Refinements in primate husbandry: a DVD teaching resource. J Med Primatol 37:97

Wolfensohn S, Honess P (2005) Handbook of primate husbandry and welfare. Oxford: Blackwell Publishing Ltd

Wolfensohn S, Finnemore P, Murphy K, Honess P, Berdoy M (2006) Endotoxic shock model with fluid resuscitation in Macaca mulatta. Lab Anim 40:102-103 